\title{
Population Aging and the Generational Economy: A Global Perspective
}

\author{
by Ronald Lee and Andrew Mason \\ Northampton MA: Edward Elgar 2011 \\ ISBN 978-1848448988 \\ Hardcover, \$199.95, 616 pp.
}

\author{
Reviewed by David K. Foot \\ Department of Economics, University of Toronto \\ foot@chass.utoronto.ca
}

It is not very often that two major issues are examined in one research volume. In this book, Lee and Mason report on a co-ordinated international project started in 2003, showing how national generational accounting can measure the impacts of population aging on government balances and the economy, while at the same time illuminating the generational winners and losers in the modern economy.

The 598 pages contain 32 chapters (appendix tables, a useful glossary, and index) separated into three main sections: four conceptual, five comparative, and twenty-three country chapters. Unfortunately, Canada is not included. The foundation for the research is the economic life cycle hypothesis for which Franco Modigliani (curiously, with only two references) received the Nobel Prize in 1985. In essence, an individual consumes above their income in the younger ages primarily because childcare (paid and unpaid) and education needs exceed low (or zero) income; consumes below their income in the working ages; and then returns to aboveincome consumption in the senior years, when income falls and healthcare needs increase. Age income profiles are "humped," but age consumption profiles (a proxy for standards of living) are almost linearly increasing. These life cycle patterns provide one justification for capital markets that allow individuals to "smooth" their consumption over the lifetime by borrowing when young (student loans, mortgages, etc.), paying back debt and saving in the mid-life working years, and then using their savings (including pensions) in the senior years.

However, as generational accounting demonstrates, reality is seldom as simple as theory. First, consumption is both private (food, housing) and public (education, healthcare). Second, many intergenerational transfers within the "family" contribute to smoothing, such as financial transfers between family members, both domestic and overseas. Third, it is useful to separate transfers to and from government, so a state pension is not income but a transfer from government (and, of course, taxes are transfers to government). Fourth, as suggested by theory, it is important to estimate contributions to (saving) and withdrawals from assets (called asset-based reallocations), both private and public. For this reason, income is defined as labour income only, with interest, dividends, and other asset income (including property income) being classified as "asset-based reallocation." Other similar measurement details are outlined in the book.

These measurements start with the System of National Accounts (SNAs), sometimes called National Income and Product Accounts. Relevant national aggregates are then assigned to individual ages, using the most appropriate national surveys. For example, Family or Household Expenditure Surveys are used to calculate age-based private consumption expenditures that also incorporate family or household composition. Information on the age composition of employees is used to estimate labour income (if more direct measures are not available). The ages of pension recipients are used to allocate aggregates to individual ages. Other government transfers are allocated in similar ways. All age-allocated aggregates are then expressed in per-capita terms, using population census information and normalized on the prime working age group (30 to 49). This normalization enables international comparisons of the results. For each country, the population numbers are used to weight the per-capita estimates and the national aggregate data applied to provide financial estimates that are consistent 
with the national totals. The resulting tables are called National Transfer Accounts (NTAs). The NTAs reflect the unique institutional features and policies of each jurisdiction in a consistent and comparable framework.

The NTAs measure the life cycle economic behaviour of the average (or representative) individual for each country. This then allows the authors to focus on the support ratio (a modified dependency ratio that takes account of all intergenerational transfers and the use of assets) to assess the implications of population aging on public sector balances and macroeconomic performance, both historically and prospectively (using relevant national population projections). The support ratio is defined as the ratio of the number of workers, weighted by the estimated age schedule of labour income, to the number of consumers, weighted by the estimated age schedule of consumption. An increase in the support ratio indicates an increase in the number of workers relative to the number of consumers, which is often referred to as a demographic dividend. Conversely, a decrease in the support ratio leads to a decrease in consumption, all other things (such as work effort, interest rates, transfers from the rest of the world, etc.) being unchanged.

The country per-capita estimates of labour income and consumption show that the average life cycle surplus occurs between the mid-20s to the late 50s, with an average working time of around 33 years. The longest of the countries in the study is Sweden at 38 (25 to 63) years, while the shortest appears to be Brazil at 20 (32.5 to 52.5) years. These estimates reflect the numerous institutional and cultural features of each society and also indicate the average length of time a life cycle deficit must be financed. There appears to be no clear pattern, except to note that the per capita deficits for the young and seniors tend to be bigger for richer countries.

The country aggregate estimates indicate that, not surprisingly, changes in the support ratio are closely associated with demographic transition, with older countries (Germany, Finland, Japan, Austria) now experiencing declining support ratios, while younger countries (Brazil, Mexico, Indonesia, Uruguay) are benefiting from increasing support ratios, at least for another decade or two. A few countries in the study (Philippines, Nigeria, Kenya) are projected to experience rising support ratios through 2050. Of course, it is how countries deal with these trends that determines the wellbeing of their inhabitants.

For example, what matters for wellbeing is not just the number of workers but also their productivity. The NTAs show that although low-fertility (and therefore rapidly aging) countries may have fewer workers in the future, those workers have often benefited from greater educational investments, which should result in higher productivity. Similarly, much of the policy discussion on the support system for seniors focuses on public transfers, often ignoring the role of private transfers and assets. Net private transfers can be important sources of support for seniors (South Korea, Taiwan, Thailand), but in some countries seniors provide substantially more support for their descendants than they receive (Brazil, Mexico, USA, Uruguay). In general, the NTAs suggest that public transfer systems are most important in Europe and Latin America, less important in USA, and least important in Asia.

The NTA findings on the use of assets are particularly interesting. Seniors in almost every economy in the study rely less on assets at older than at younger ages. This finding would appear to support the life cycle hypothesis that they are using up their assets as they age, but the authors note (on p. 23) that "this interpretation appears to be wrong in almost every society. With rare exceptions, the elderly are not dissaving." Older seniors have less wealth because of lower labour income in their working years, which they earned in the more distant past, and therefore were never able to accumulate as much wealth as the young seniors. Since the NTAs show that on average seniors have relatively high asset income and continue to save throughout their lives in most countries, population aging will likely lead to increased asset accumulation and capital per worker, thereby reinforcing the educational impact on productivity discussed above. It would be useful if the current discourse on dependency and future government balances was expanded to include these observations.

As carefully noted by the authors, the estimated age profiles that underlie the NTAs are cross-sectional, whereas true economic life cycles are longitudinal. This is less likely to be an issue in well-established economies undergoing little economic change, but is more likely to be an issue in economies undergoing rapid economic growth. Also, these estimated life cycle profiles are tied to the SNAs, and therefore, do not incorporate the value of time devoted to home production or to care for children or the elderly. It is important to bear these limitations in mind when interpreting the results. 
Unfortunately, this book's use to Canadian researchers is limited by the omission of Canada from the list of included countries. It is tempting to "guesstimate" outcomes for Canada, perhaps by positioning the country between USA and Europe, but given some of the detailed findings in the individual country chapters, this could be dangerous. The project website (www.ntaccounts.org) includes estimates for some additional countries not included in this volume, but not, as yet, Canada. The Canadian contact for this project is listed as the University of Ottawa.

[Editor's note: This book review was received in October 2012]. 